\section{Time to leave the palace?}

Duncan Davies $€ 92$

ICI: The Company That Changed Our Lives. By Carol Kennedy.

Hutchinson: 1986. Pp.209. £12.95.

Nineteen eighty six is an ideal year in which to write an anecdotal and journalistic storybook about ICI, to help us all understand the reasons for the success of the chemical industry during the past century. All is well with the time, the place and the loved one. If he were less modest, Sir John Harvey-Jones, the current chairman, could well say that the Firm is the true embodiment of everything that's excellent; it neither makes one sweat or squirm, for he, my Lords, embodies the Firm; The Company That Changed Our Lives, as the title has it.

First, 1986 is ICI's Diamond Jubilee. Secondly, the process of chemical invention really has transformed do-it-yourself home improvement, medicine and farming by taking systematically designed products and processes massively and profitably into craft industries. Thirdly, most of the inventors are, happily, still with us, and can tell their stories to the troubadour. Fourthly, there is a scholarly official history as an alternative source. Fifthly, the market and socio-economic conditions have been favourable to the chemical industry's talents for the whole of the past half-century, and have only just started to change. And finally, ICI itself has a record of inventive and innovative achievement that is second to none.

Carol Kennedy's treatment is racy and circumstantially persuasive, so that the book is an excellent read and should interest people who hitherto have regarded company history as prosy or incomprehensible. It was admirable to publish the book in November, and thereby include events in September, but such briskness means that there are quite a few mistakes. One of these gives a misleading picture of the reason for the British lag in the development of penicillin; others are trivial, and in total are no more than an acceptable price for a history of this kind. The harp is well-tuned and the hall has good acoustics. The photos are right.

The reader must, however, beware of the implied assumption that the commercial success in the civil market of a sequence of chemically-led inventions will continue indefinitely. Current difficulties in cashing in on innovations every bit as good as those of the past are presented as bad luck, of the kind that is inevitable from time to time. This cheerful interpretation may be wrong; it is possible that the rules are changing. Carol Kennedy's storybook has a last chapter on 2026 - the year of the ICI centenary - which rather suggests that more of the same will continue to succeed as before. So there is no real discussion of the fact that many of the key materials for space vehicles and military systems are not finding their way into civil use anything like as readily as they used to. Large subsidies supporting new technology in agriculture have fed the hungry and are now creating very big surpluses, tation of the future work of Professor Birchall and his colleagues in the New Science Group of ICI.

Clues for the successful design of the agencies that in 2026 will have taken over ICI's baton lie in the fact that all organizations are the prisoners of their past successes. Study of the reasons why ICI has had to spend very large tranches of its recent pharmaceutical and agricultural earnings in supporting its polythene and polyester businesses, through processes that culminated in divestment, gives glimpses of hazards in the path of its Pharmaceutical Division. The engaging and valuable storybook that omits these points is insufficient, and is misleading if it is assumed that the sleeping princess awoken by Harvey-Jones can now live happily ever

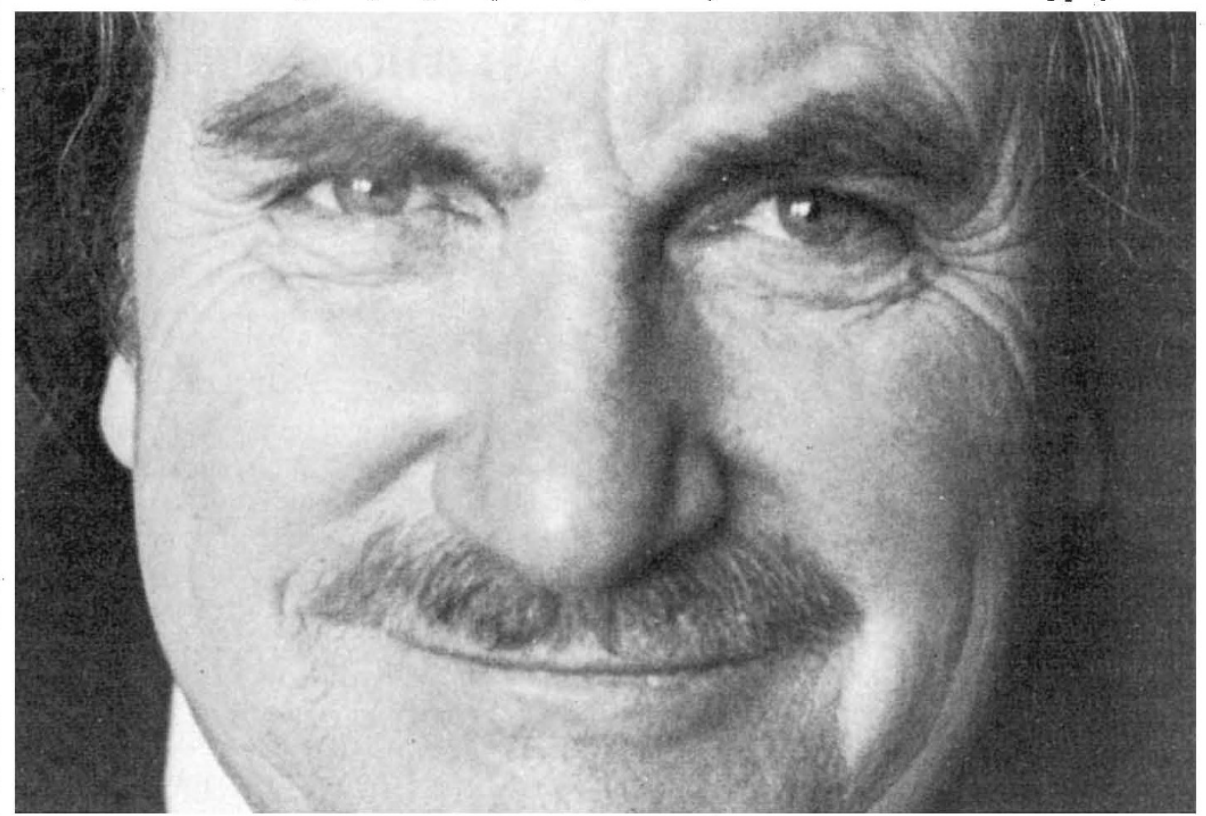

Embodiment of ICI - John Henry Harvey-Jones, who retires as chairman on 31 March.

yet this is not raised as a constraint on profits dependent on further stimulation of farm yields. The decreasing rate and escalating net cost of pharmaceutical innovations are not seen to be possible indicators that new computers and biology may replace straightforward chemistry as the lead element in the next round of medical advance. The development of medical services and the pharmacopoeia may be much more closely tied together in future.

Altogether, there are strong arguments that the past chemical century is not the beginning of a thousand-year Reich. The likelihood is that from now on, in the words of an ICI Chairman, "it's going to be very different", with the chemical industry beneficially exploding into a dozen separate daughter industries that use chemistry, sometimes in a subservient role, alongside other skills. If this is so, then the fissile changes set in train by Harvey-Jones and others are going to be essential for the socially profitable exploi- after, in the same palace and without any special or structural reforms.

Danny Kaye once made a film called The Court Jester, in which there was disastrous confusion between the chalice from the palace (which contained the pellet with the poison) and the vessel with the pestle (which contained the brew that is true). We may be in the middle of a macro re-run. The palatial methods of the present chemical industry will go on earning profits for some decades to come, but well-being in 2026 will almost certainly depend on the recognition, acceptance and exploitation of quite new market and social conditions, calling for new assemblies of skills. Only then will Professor Birchall and others escape from some of their growing frustrations.

Duncan Davies, 3 Broadlands Close, London N6 4AF, is Chairman of British Ceramics Research Ltd and President of the Society of Chemical Industry. He was the General Manager of Research and Development at ICI in the years 1969-1977. 